\title{
Activated carbon prepared from coffee pulp: potential adsorbent of organic contaminants in aqueous solution
}

\author{
Maraisa Gonçalves, Mário César Guerreiro, Paulize Honorato Ramos, \\ Luiz Carlos Alves de Oliveira and Karim Sapag
}

\begin{abstract}
The processing of coffee beans generates large amounts of solid and liquid residues. The solid residues (pulp, husk and parchment) represent a serious environmental problem and do not have an adequate destination. In this work, activated carbons (AC) for adsorption of organic compounds were prepared from coffee pulp by controlled temperature at different pulp/ $\mathrm{Na}_{2} \mathrm{HPO}_{4}$ ratios $(4: 1,2: 1,5: 4$ and 1:1). The $\mathrm{N}_{2}$ adsorption/desorption isotherms showed $\mathrm{AC}$ with high quantities of meso and micropores and specific surface areas of $140,150,450$ and $440 \mathrm{~m}^{2} \mathrm{~g}^{-1}$ for $A C 4: 1, A C 2: 1, A C 5: 4$ and $A C 1: 1$, respectively. The prepared material $A C 5: 4$ showed a higher removal capacity of the organic contaminants methylene blue (MB), direct red (DR) and phenol than a Merck AC. The maximum capacities for this AC are approximately 150,120 and $120 \mathrm{mg} \mathrm{g}^{-1}$ for MB, DR and phenol, respectively. Thus, a good adsorbent was obtained from coffee pulp, an abundant Brazilian residue. Key words | activated carbon, adsorption, coffee pulp, environmental pollutants

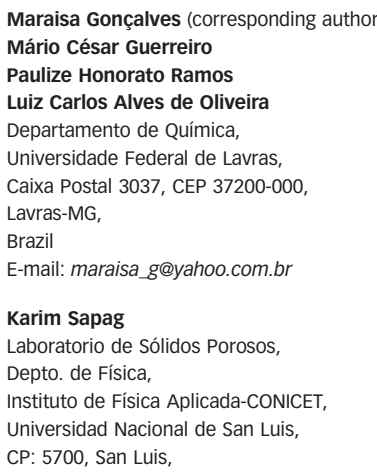

\section{INTRODUCTION}

In Brazil, the coffee fruit processing is one of the most pollutant activities in agriculture due to a large amount of bean production (2.4 million tons/year). Each kilogram of processed coffee yields a kilogram of waste (Lu et al. 20II;

Q1 Conab 20I2). This large amount of coffee waste (husk, parchment and pulp) has to be controlled, since its inadequate disposal can contaminate water resources and soils. This motivates the search for obtaining value-added products from coffee waste, such as activated carbons (AC), as well as the attempt to solve some environmental problems Q2 (Pandey et al. 2000).

AC have been extensively used as adsorbents and as catalyst supports in a variety of industrial and environmental applications such as hazardous pollutant removal. Commercial AC are widely used, but their high cost leads to explore alternative raw materials like agricultural and wood wastes such as coconut husk fiber, fruit kernels, rice husks, leather, jute and coffee wastes that appear to be economically more attractive in some countries due to their availability (Mohan et al. 2005; Oliveira et al. 2007, 2008; Moreno-Castilla et al. 20II; Ruiz-Fernandez et al. 20II).

In the bibliography, $\mathrm{AC}$ prepared from coffee waste with different activating agents as $\mathrm{ZnCl}_{2} \mathrm{H}_{3} \mathrm{PO}_{4}, \mathrm{~K}_{2} \mathrm{CO}_{3}, \mathrm{FeCl}_{3}$ have been reported (Nabais et al. 2008a, 2008b; Rios et al. Q3 2009; Castro et al. 20II; Goncalves et al. 20I2). However, information on coffee husk activated with $\mathrm{Na}_{2} \mathrm{HPO}_{4}$ is very scarce. The aim in this work is the study of the activation of coffee pulp with $\mathrm{Na}_{2} \mathrm{HPO}_{4}$ and its utilization in organic pollutants removal, such as direct red (DR), methylene blue (MB) and phenol. One commercial AC from Merck was used to compare with the prepared AC in the adsorption of these contaminants from aqueous medium.

\section{EXPERIMENTAL}

\section{Preparation of activated carbons}

To prepare the AC, $10 \mathrm{~g}$ of coffee pulp (dried at $100{ }^{\circ} \mathrm{C}$ for $24 \mathrm{~h}$ ) was mixed with different amounts of disodium hydrogen phosphate $\left(\mathrm{Na}_{2} \mathrm{HPO}_{4}\right)$, in order to obtain the impregnation ratios (pulp: $\mathrm{Na}_{2} \mathrm{HPO}_{4}$ ) $4: 1 ; 2: 1 ; 5: 4$ and $1: 1$. The final samples were kept for $24 \mathrm{~h}$ at $110{ }^{\circ} \mathrm{C}$ and then activated in a tubular oven (Lindberg Blue) under $\mathrm{N}_{2}$ flow $\left(100 \mathrm{~mL} \mathrm{~min}^{-1}\right)$ at a heating rate of $10{ }^{\circ} \mathrm{Cmin}^{-1}$ until $825^{\circ} \mathrm{C}$ and kept for $1 \mathrm{~h}$. After this activation process, the 
excess of $\mathrm{Na}_{2} \mathrm{HPO}_{4}$ was removed with a $5 \mathrm{M}$ solution of $\mathrm{HCl}$, and then washed with hot distilled water until neutral $\mathrm{pH}$.

\section{Characterization}

Analysis of carbon, hydrogen, oxygen and nitrogen elementals (CHNO) were carried out in a CNH 500A Shimadzu equipment. Textural characterization was performed with an AUTOSORB-1MP analyzer from Quantachrome Corp., by nitrogen adsorption/desorption isotherms at $-196^{\circ} \mathrm{C}$. The specific surface area from $\mathrm{N}_{2}$ adsorption isotherm was calculated with the Brunauer, Emmett and Teller (BET) method and the pore size distribution was plotted using the Density Functional Theory (DFT) method for AC. The micropore volume was calculated by Dubinin-Radushkevich equation and the mesopore volume by the difference between the total pore volume $\left(V_{0,95}\right)$ and the micropore volume. The ash content was determined by thermogravimetry (TG) (TGA-DTA Shimadzu MOD 8065 D1) at $950{ }^{\circ} \mathrm{C}$ in air atmosphere with a heating rate of $20{ }^{\circ} \mathrm{C} \mathrm{min}^{-1}$.

X-ray photoelectron spectroscopy (XPS) was used to examine the surface chemistry. The measurements were performed with a spectrometer (Kratos Analytical XSAM 800 cpi) with $\mathrm{Mg} \mathrm{K} \alpha$ radiation $(1,253.6 \mathrm{eV})$ as the X-ray source.

\section{Adsorption tests}

The AC were used in adsorption tests in aqueous solution with three well-known organic pollutants: MB organic dye, DR organic dye and phenol. The adsorption tests (three replications) were conducted in a batch system with solutions of $25,50,100,250,500$ and $1,000 \mathrm{mg} \mathrm{L}^{-1}$ of the organic pollutants. To obtain the adsorption isotherms, the solutions $(10 \mathrm{~mL})$ were left in contact with the adsorbent materials $(10 \mathrm{mg})$ for a period of $24 \mathrm{~h}$ and then they were centrifuged at 8,300 $\mathrm{g}$ for $25 \mathrm{~min}$. The collected supernatants were analyzed by UV-visible spectroscopy (Biosystems SP-2000) at the following wavelengths $\left(\lambda_{\text {max. }}\right): 665 \mathrm{~nm}$ for $\mathrm{MB}, 543 \mathrm{~nm}$ for DR dye and $275 \mathrm{~nm}$ for phenol.

\section{RESULTS AND DISCUSSION}

\section{Characterization of the activated carbon (AC)}

The nitrogen adsorption/desorption isotherm and pore distribution are shown in Figure 1 and the textural properties (specific surface and pore volumes) are shown in Table 1.

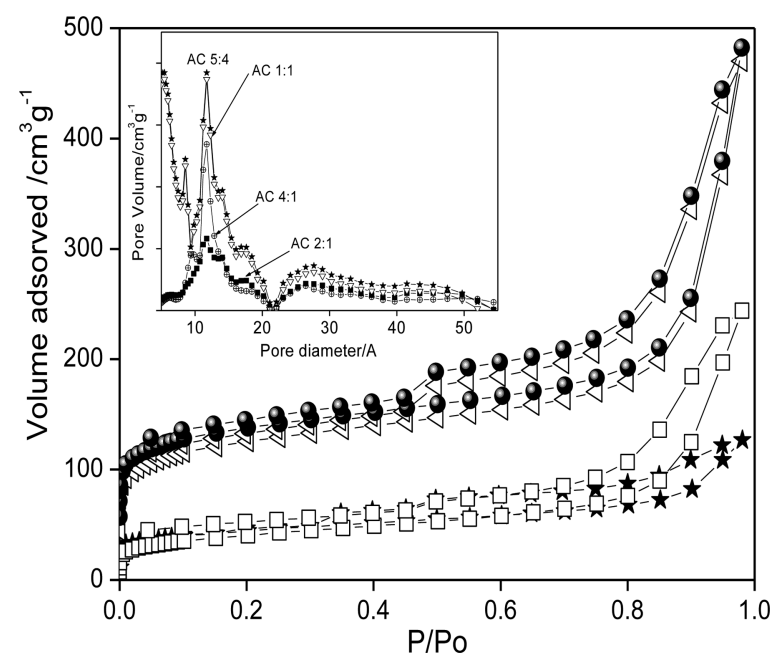

Figure 1 | Nitrogen adsorption/desorption $\left(-196^{\circ} \mathrm{C}\right)$ isotherms and pore distribution for all activated carbons (star AC 4:1; square AC 2:1; circle AC 5:4 and triangle $A C$ $1: 1)$.

Table 1 | Surface area, porosity and elementary analysis $(\mathrm{CHO})$ and ash of activated carbons and coffee pulp

\begin{tabular}{clllllll} 
Sample & $\begin{array}{l}\boldsymbol{S}_{\mathbf{B E T}} \\
\mathbf{m}^{\mathbf{2}} \mathbf{g}^{-\mathbf{1}}\end{array}$ & $\begin{array}{l}\boldsymbol{V}_{\mathbf{m i c r o}} \\
\mathbf{c m}^{\mathbf{3}} \mathbf{g}^{-\mathbf{1}}\end{array}$ & $\begin{array}{l}\mathbf{V}_{\mathbf{m e s o}} \\
\mathbf{c m}^{\mathbf{3}} \mathbf{g}^{-\mathbf{1}}\end{array}$ & $\mathbf{C} \%$ & $\mathbf{H} \%$ & $\mathbf{0} \%$ & $\begin{array}{l}\text { Ash } \\
\%\end{array}$ \\
\hline $\begin{array}{c}\text { Coffee } \\
\text { pulp }\end{array}$ & $<10$ & - & - & 39 & 5.4 & 54 & 1 \\
AC 4:1 & 140 & 0.06 & 0.05 & 67 & 1.6 & 30 & 1 \\
AC 2:1 & 155 & 0.08 & 0.07 & 67 & 2.3 & 29 & 2 \\
AC 5:4 & 451 & 0.17 & 0.22 & 68 & 1.4 & 29 & 2 \\
AC 1:1 & 444 & 0.16 & 0.21 & 69 & 1.4 & 28 & 3 \\
AC & 670 & 0.26 & 0.10 & - & - & - & 1 \\
Merck & & & & & & & \\
\hline
\end{tabular}

The nitrogen adsorption/desorption isotherms showed isotherm types I and IV. The hysteresis is attributed to the adsorption by mesoporous materials (Sing et al. I985). However, important adsorption at low and intermediate relative pressures is also shown, indicative of the simultaneous presence of micro and mesopores (Figure 1).

The chemical activation by different quantities of $\mathrm{Na}_{2} \mathrm{HPO}_{4}$ produced materials with different characteristics (Table 1). The specific surface area increases with the increasing of activating agent mass proportion (pulp/ $\mathrm{Na}_{2} \mathrm{HPO}_{4}$ ) ratios until 5:4, producing an $\mathrm{AC}$ with $450 \mathrm{~m}^{2} \mathrm{~g}^{-1}$ and micro-mesoporous carbons $\left(V_{\mathrm{N} 2}=0.17 \mathrm{~cm}^{3} \mathrm{~g}^{-1}\right.$ and $\left.V_{\text {meso }}=0.22 \mathrm{~cm}^{3} \mathrm{~g}^{-1}\right)$. These proprieties are comparable to other ACs from coffee waste reported in the literature by Nabais et al. (2008a, 2008b) with surface area of 
$260-800 \mathrm{~m}^{2} \mathrm{~g}^{-1}$. The AC from Merck is a microporous materials with a specific surface area of $670 \mathrm{~m}^{2} \mathrm{~g}^{-1}$.

The ACs ash contents are low (about 3\%), this can be due to $\mathrm{Na}_{2} \mathrm{HPO}_{4}$ residues (confirmed by XPS analysis). The elemental analysis results (Table 1) showed an increase of carbon content and a decrease of oxygen contents after activation, however, it did not show a significant difference between different ACs.

The profile of XPS spectra in the O1s region of AC 4:1 and AC 2:1 are similar, as well as the profiles for AC 5:4 and AC 1:1. Figure 2 shows the profiles for AC 4:1 and AC 1:1.

The O1s AC spectrum was fitted to three peaks: Peak I 530.7-531.2 eV, corresponding to double bond oxygen in quinones, carbonyl groups or $\mathrm{O}=\mathrm{P}$; Peak II $532.5 \mathrm{eV}$, corresponding to $\mathrm{C}-\mathrm{OH}$ of phenol and alcohol groups; and Peak III $534.2 \mathrm{eV}$, characteristic binding energy of carboxylic groups (Puziy et al. 2006). These groups are very important in the adsorption process, especially for polar molecules, such as those evaluated in this work.

The amount of oxygen quantified by XPS analysis is less than that quantified by elemental analysis. This may be due to differences between the techniques; XPS is only a superficial analysis.

In summary, the physicochemical characterization of the ACs prepared in this work showed that they presented high surface area, with the presence of meso and microporosity, together with oxygen-rich surface groups.

\section{Adsorption tests}

Liquid phase adsorption applies to many processes, the wastewater treatment being one of the most relevant.
Textile dyes and phenol are relatively large pollutants from industrial processes. In this work two dyes and phenol were used in the adsorption tests. MB is a cationic organic compound, medium sized; most used as a model compound in aqueous solution (Stavropoulos \& Zabaniotou 2005). DR is an anionic dye of large size. It is most used in the textile industry. Phenol is a small molecule, very toxic and carcinogenic, not biodegradable, so when it is discharged into wastewaters it presents a serious environmental problem.

Figure 3 shows the molecular structure of all contaminants (a) and the influence of initial $\mathrm{pH}$ on the adsorption of contaminants onto AC 5:4 (b).

The results suggest that the adsorptions of dyes and phenol in aqueous solution are highly dependent on solution $\mathrm{pH}$. The increase of DR adsorption under acid conditions may be explained by preference of anionic molecules for acid sites and their easy accessibility in the AC pores (Ugurlu et al. 2007). For cationic species (MB), an increase of $\mathrm{pH}$ increased the color removal, due to the electrostatic attraction between the AC surface and the dyes. The phenol adsorption shows an optimum $\mathrm{pH}$ value of 2. The other $\mathrm{pH}$ values evaluated did not show significant differences. This is due to the phenol $\mathrm{p} K_{\mathrm{a}}$ value (9.8), in $\mathrm{pH} 2$, where there is no electrostatic repulsion between the non-ionized phenol and the positively charged surface (Kennedy et al. 2007). The oxygen and phosphorous of surface groups are highly affected by $\mathrm{pH}$, consequently, this can have an influence on the AC adsorption capacity.

However due the difficulty of $\mathrm{pH}$ control for $24 \mathrm{~h}$ we performed all experiments in the natural $\mathrm{pH}$ of the solution.

The adsorption isotherms for dyes on the AC surface are shown in Figure 4.
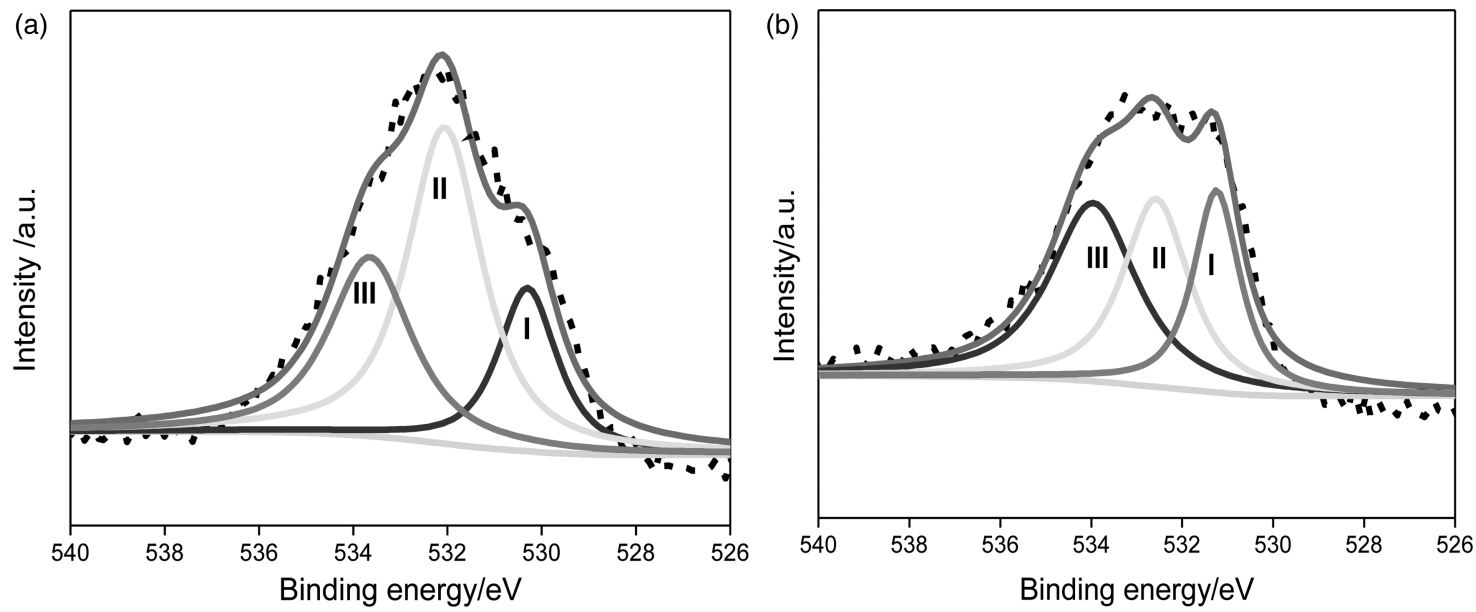

Figure 2 | XPS spectrum of AC: (a) AC 4:1 and (b) AC 1:1. 
(a)

Methylene Blue<smiles>CN(C)c1ccc2nc3ccc(=[N+](C)C)cc-3sc2c1</smiles>

Phenol<smiles>Oc1ccccc1</smiles>

Direct red

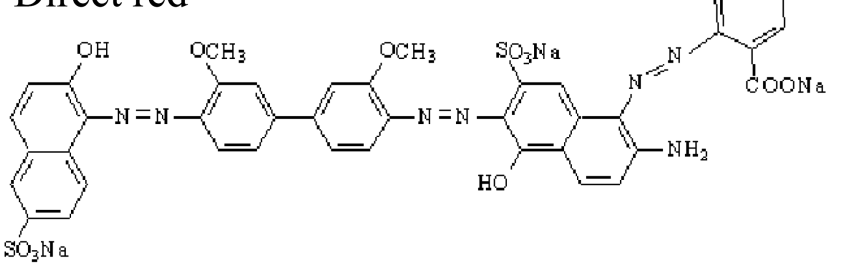

(b)

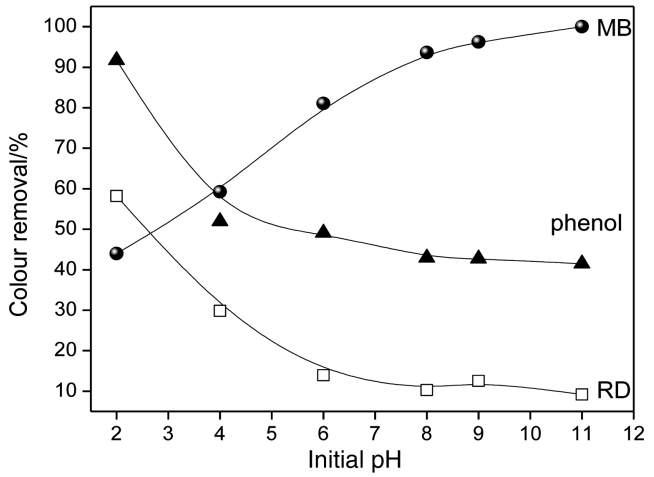

Figure 3 | Structure of contaminants (a) and influence of initial pH on the adsorption of dyes and phenol onto AC 5:4 (b). Conditions: room temperature, concentration 100 mg $\mathrm{L}^{-1}$ and $\mathbf{Q} 6$ adsorption time $5 \mathrm{~h}$.
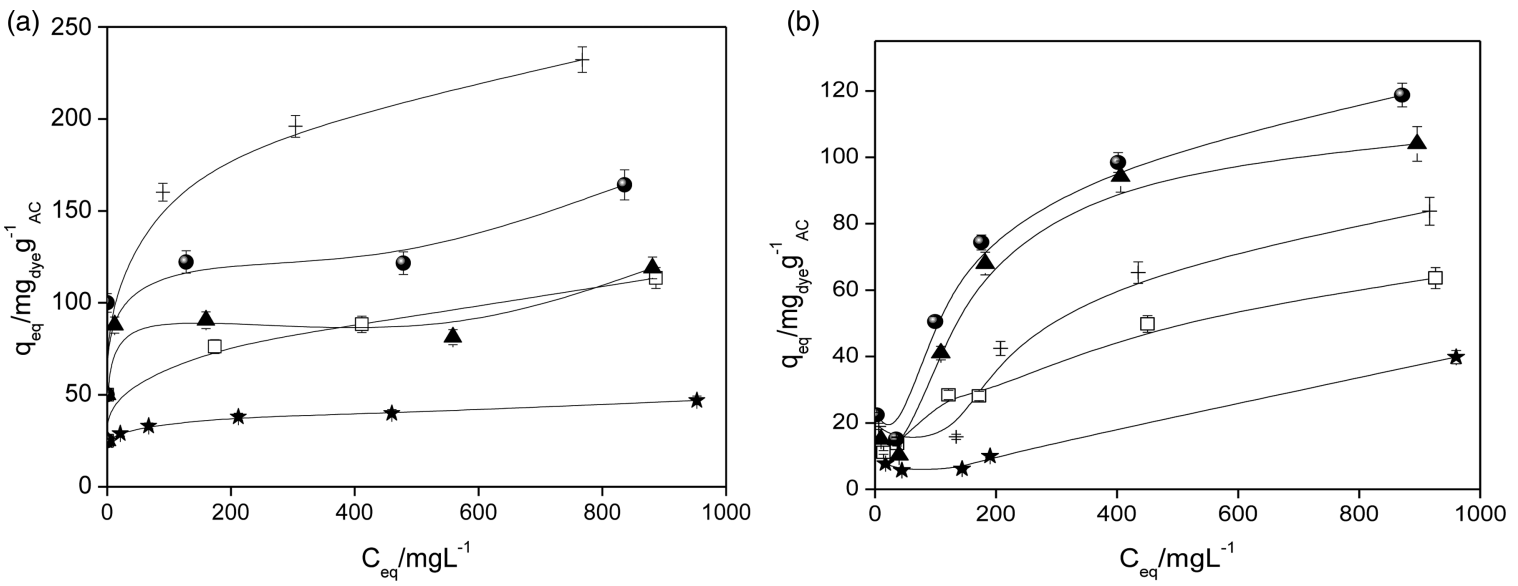

Figure 4 | Adsorption isotherms of dyes on the AC surface: (a) MB and (b) DR ( $\mathrm{pH} 5.0 \pm 0.5$ ) (star AC 4:1; square AC 2:1; circle AC 5:4; triangle AC 1:1 and cross AC Merck).

The maximum adsorption of MB (Figure 4(a)) obtained for AC 5:4 and AC 1:1 were 150 and $110 \mathrm{mg} \mathrm{g}^{-1}$, respectively. This difference can be due to the higher surface area of AC 5:4. Adsorption isotherms can be classified as type L or Langmuir model, it is a typical model for monolayer adsorption.

For DR, the more efficient removal was obtained at AC 5:4 and AC 1:1 with adsorption capacity of approximately 120 and $98 \mathrm{mg} \mathrm{g}^{-1}$, respectively. The adsorption capacity is higher than commercially AC (Merck) with maximum of
$70 \mathrm{mg} \mathrm{g}^{-1}$. This is probably due to the pore diameters shown for AC 5:4 and 1:1, 20 and 24 A, respectively.

The adsorption isotherms for the phenol on the AC are shown in Figure 5.

There are three types of interaction between the carbon surface and phenols (a) dispersion effect between the aromatic ring and the $\pi$ electrons of the graphitic structure; (b) electron donor-acceptor interaction between the aromatic ring and the basic surface oxygens; (c) electrostatic attraction and repulsion when ions are 


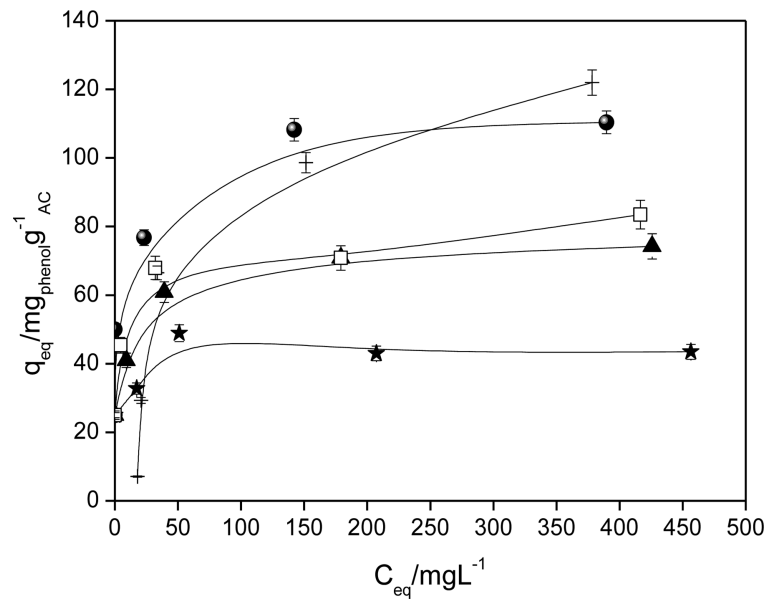

Figure 5 | Adsorption isotherms of phenol on the activated carbon surface $(\mathrm{pH} 6.0 \pm 0.5)$ (star AC 4:1; square AC 2:1; circle AC 5:4; triangle AC 1:1 and cross $A C$ Merck)

present (Kennedy et al. 2007; Lu et al. 20II). When the concentration of the oxygen atoms is relatively high, the specific interaction between the water molecules and the surface sites must also be considered, since it results in the depletion of the phenol adsorption sites. The Langmuir type means that the aromatic ring adsorbs parallel to the graphitic surface, and there is no strong competition between the adsorbent and the solvent to occupy the surface sites. The best adsorbent AC for phenol was 5:4 or the AC with the highest specific surface area. The linearized Langmuir parameters showed very good correlation Q4 (Table 2).

The adsorption of carbon prepared in this work is similar to that reported for the adsorption of acid orange 10 dye onto AC prepared from agricultural waste bagasse (Tsai et al. 200I), by the MB adsorption on AC prepared from food sludge (Mahapatra et al. 2012) and dyes and phenol adsorption onto carbon cryogel microspheres (Kim et al. (2006).

\section{CONCLUSION}

The coffee pulp waste is a very interesting precursor for AC preparation; therefore we added value to an abundant waste. The results presented in this work show that an AC with high amount of mesopores and oxygen surface groups can be obtained in a very simple method and with a low proportion of activating agent.

The AC showed high removal capacity for organic contaminants in aqueous medium. In summary, we obtained an AC from a waste with good characteristics: high micro and mesoporous content with adsorption capacity for large and polar molecules.

\section{ACKNOWLEDGEMENTS}

The authors would like to acknowledge CAPQ/DQI, CAPES, FAPEMIG and CNPq for supporting this work.

\section{REFERENCES}

Castro, C. S., Abreu, A. L., Silva, C. L. \& Guerreiro, M. C. 20 II Phenol adsorption by activated carbon produced from spent coffee grounds. Water Science and Technology 64, 2059-2065.

Conab, Companhia nacional de abastecimento: Safra café 2012 http://www.conab.gov.br/OlalaCMS/uploads/arquivos/ 12_05_10_08_56_04_boletim_cafe_-_maio_2012.pdf (2012). (Accessed 20 june 2012).

Goncalves, M., Guerreiro, M. C., Oliveira, L. C. A., Solar, C., Nazzarro, M. \& Sapag, K. 2012 Micro mesoporous activated carbon from coffee husk as biomass waste for environmental applications. Waste and Biomass Valorization.

Kennedy, L. J., Vijaya, J. J., Kayalvizhi, K. \& Sekaran, G. 2007 Adsorption of phenol from aqueous solutions using mesoporous carbon prepared by two-stage process. Chemical Engineering Journal 132, 279-287.

Kim, S. I., Yamamoto, T., Endo, A., Ohmori, T. \& Nakaiwa, M. 2006 Adsorption of phenol and reactive dyes from aqueous solution on carbon cryogel microspheres with controlled porous structure. Microporous and Mesoporous Materials 96, 191-196.

Lu, G., Hao, J., Liu, L., Ma, H., Fang, Q., Wu, L., Wei, M. \& Zhang, Y. 2oII The adsorption of phenol by lignite activated carbon. Chinese Journal of Chemical Engineering 19, 380-385.

Mahapatra, K., Ramteke, D. S. \& Paliwal, L. J. 2012 Production of activated carbon from sludge of food processing industry under controlled pyrolysis and its application for methylene blue removal. Journal of Analytical and Applied Pyrolysis 95, 79-86.

Mohan, D., Singh, K. P., Sinha, S. \& Gosh, D. 2005 Removal of pyridine derivatives from aqueous solution by activated carbons developed from agricultural waste materials. Carbon 43, 1680-1693.

Moreno-Castilla, C., Fontecha-Cámara, M. A., Álvarez-Merino, M. A., López-Ramón, M. V. \& Carrasco-Marín, F. 2on Activated carbon cloth as adsorbent and oxidation catalyst for the removal of amitrole from aqueous solution. Adsorption 17, 413-419.

Nabais, J. M. V., Nunes, P., Carrott, P. J. M., Ribeiro Carrott, M. M. L., Garcia, A. M. \& Diaz-Diesz, M. A. 2008a Production of activated carbons from coffee endocarp by $\mathrm{CO}_{2}$ and steam activation. Fuel Processing Technology 89, 262-268. 
Nabais, J. M. V., Carrott, P., Ribeiro Carrott, M. M. L., Luz, V. \& Ortiz, A. L. 2008b Influence of preparation conditions in the textural and chemical properties of activated carbons from a novel biomass precursor: the coffee endocarp. Bioresource Technology 99, 7224-7231.

Oliveira, D. Q. L., Gonçalves, M., Oliveira, L. C. A. \& Guilherme, L. R. G. 2008 Removal of $\mathrm{As}(\mathrm{V})$ and $\mathrm{Cr}(\mathrm{VI})$ from aqueous solutions using solid waste from leather industry. Journal of Hazardous Materials 151, 280-228.

Oliveira, L. C. A., Gonçalves, M., Oliveira, D. Q. L., Guerreiro, M. C., Guilherme, L. R. G. \& Dallago, R. M. 2007 Solid waste from leather industry as adsorbent of organic dyes in aqueousmedium. Journal of Hazardous Materials 141, 344-347.

Puziy, A. M., Poddubnaya, O. I. \& Ziatdinov, A. M. 2006 On the chemical structure of phosphorus compounds in phosphoric acid-activated carbon. Applied Surface Science 252, 8036-8038.

Rios, R. B., Silva, F. W. M., Torres, A. E. B., Azevedo, D. C. S. \& Cavalcante, C. L. 2009 Adsorption of methane in activated carbons obtained from coconut shells using $\mathrm{H}_{3} \mathrm{PO}_{4}$ chemical activation. Adsorption 15, 271-277.
Ruiz-Fernandez, M., Alexandre-Franco, M., Fernández-González, C. \& Gómez-Serrano, V. 2orn Development of activated carbon from vine shoots by physical and chemical activation methods. Some insight into activation mechanisms. Adsorption 17, 621-629.

Sing, K. S. W., Everett, D. H., Haul, R. A. W., Moscou, L., Pierotti, R. A., Rouquerol, J. \& Siemieniewska, T. 1985 Reporting physisorption data for gas/solid systems with special reference to the determination of surface area and porosity. International Union Pure Applied Chemistry 54, 603-619.

Stavropoulos, G. G. \& Zabaniotou, A. A. 2005 Production and characterization of activated carbons from olive-seed waste residue. Microporous and Mesoporous Materials 82, 79-85.

Tsai, W. T., Chang, C. Y., Lin, M. C., Chien, S. F., Sun, H. F. \& Hsieh, M. F. 20or Adsorption of acid dye onto activated carbons prepared from agricultural waste bagasse by $\mathrm{ZnCl}_{2}$ activation. Chemosphere 45, 51-58.

Ugurlu, M., Gürses, A. \& Dogar, C.. 2007 Adsorption studies on the treatment of textile dyeing effluent by activated carbon prepared from olive stone by $\mathrm{ZnCl}_{2}$ activation. Coloration Technology 123, 106-114.

First received 31 December 2012; accepted in revised form 22 April 2013 


\section{Author Queries}

\section{Journal: Water Science \& Technology}

Manuscript: wst-em1326r3

Q1 Please confirm the correct year of Conab (2012) as per the reference list.

Q2 Pandey et al. (2000) is not listed in the reference list. Please provide publication details to insert in the list.

Q3 Please confirm whether Nabais et al. (2008) should be changed to Nabais et al. (2008a, b) both in text and reference list.

Q4 Table 2 is cited in text, but not provide. Please check.

Q5 Please provide volume and page numbers for Goncalves et al. (2012).

Q6 In supplied Figure 1(a) is not sufficient print quality. Please resupply as a high resolution file (300 dpi or above) with sharp lines and text. 